Rev. Elev. Méd, Vét. Pays trop., 1967, 20, 1 (125-127)

\title{
Note sur une polyavitaminose B des oiseaux de cage au Sénégal
}

\author{
par M. P. DOUTRE, H. CALVET ef J. CHAMBRON
}

\begin{abstract}
RÉSUMÉ
Les auteurs ont observé des cas de polyavitaminose B survenus chez des oiseaux entretenus en volière dans la région de Dakar avant, leur exportation.

Les conditions d'entretien et d'alimentation sont précisées.

Au labaratoire les auteurs ont obtenu une régression rapide des symptômes en administrant aux oiseaux des extraits de levure, de la thiamine ou de la riboflavine.
\end{abstract}

Dans l'attente d'expéditions sur les marchés extérieurs, un exportateur d'oiseaux de la région de Dakar entrepose différents passereaux dans une pièce de dimensions suffisantes. Plusieurs mililiers de petits volatiles peuvent ainsi demeurer dans cette enceinte pendant un temps prolongé.

L'aménagement du local comporte de nombreux perchoirs en échelle, des abreuvoirs du type utilisé en aviculture et un bac en ciment rempli de grit (sable fin). L'alimentation, disposée sur le sol en abondance, est constituée essentiellement par un mélange de graınes broyées de petit mil local ou souno (Pennisetum typhoideum) et de fonio (Digitaria exilis). En outre, à la suite de conseils divers, le propriétaire a pris l'habitude d'adjoindre à l'eau de boisson une médıcatıon destinée à lutter contre la salmonellose (Salmonella typhi-murum). Différents produits ont été successivement essayés avec des résultats médiocres sinon nuls, les deux derniers en date étant l'auréomycine et la terramycine. Chaque matin, les cadavres et les malades manifestement à l'agonie sont éliminés.

Au cours d'une visite, l'osseleur attira notre attention sur des individus qui présentaient des troubles nerveux flagrants : torticolis, opisthotonos, position assise avec ou non appui sur l'extrémité des ailes, contracture des doigts démarche ataxique, déséquilibre, convulsions, etc... (photos).

Les oiseaux touchés par l'affection appartenaient aux espèces suivantes :

Bec d'argent (Euodice contans),

Cou coupé (Amadina fosciata),

Serın du Mozambique (Serinus mozambicus), Bruant cannelle (Fringillaria tahopisi gosingi), Mange-mil ou travailleur (Quelea queleo queleo).

La maladie, remarquée de longue date, se propage insidieusement ; chaque jour, environ une trentaine d'oiseaux nouveaux offrent le comportement anormal décrit ci-dessus. L'évoIution, toujours fatale, peut durer une semaine. Pendant cette période, l'appétit se maintient comme à l'ordınaire.

Après avoir éliminé l'action possible d'un agent infectieux (maladie de Newcastle), l'hypothèse d'une polycarence en vitamines du groupe $B$ a été retenue, le tableau clinique présenté étant analogue en tout point à celui du béribéri décrit chez les volailles $(4,5,6)$.

L'origine nutritionnelle de l'affection a été mise en évidence au laboratoire en soumettant des lots différents d'osseaux malades à une alimentation à base de graines auxquelles était adjoint soit de l'extrait de levure (Yeast extract 

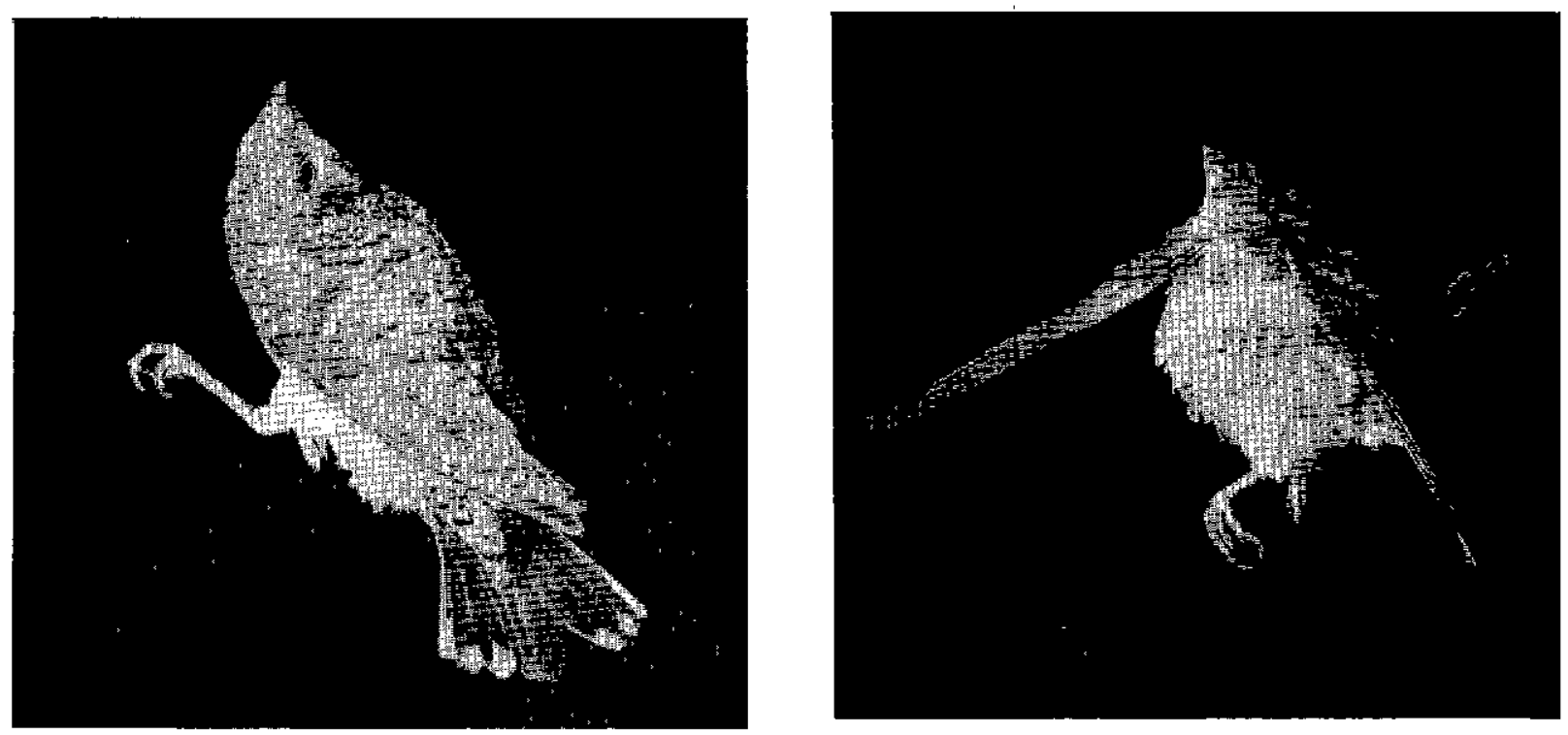

Photos 1 et 2. - Troubles nerveux chez un cou coupé (Amadina fasciata) atteınt de « béribéri ».

Difco), soit de la thiamine (Merck), soit de la riboflavine (Hoffmann La Roche).

Chez les animaux qui reçurent l'extrait de levure ou la thiamine, les symptômes régressèrent rapidement; en 48 heures et même en 24 heures chez certains sujets, tous les troubles avaient disparu. Les oiseaux traités par la riboflavine manifestèrent une amélioration d'état nette mais non totale, persistaient : le plumage gonflé et une tendance marquée à la somnolence. Ces derniers signes s'estompèrent après absorption d'extrait de levure ou de thiamine.

A quoi peut-on rapporter les origines de cette carence développée par ces oiseaux de volière?

Le grit ne semble pas être en cause; dans le sable disposé d̀ leur intention, les passereaux trouvent tous les éléments dont ils ont besoin (9). Par contre, il est possible que le mélange de souna et de fonio puisse être incriminé. Dans le passé, l'exportateur avait l'habitude d'adjoindre des graines de moha (Setaria germanica) ef de millet en provenance d'Europe. Pour réduire ses frais, ॥l a cessé cette pratique. Si la ration n'est pas critiquable dans sa composition qualitative et quantitative - et le fait reste à démontrer - elle offre certainement une trop grande uniformité qui éloigne l'osseau des conditions alimentaires qu'il trouve dans la nature. Les antibiotıques (auréomycine, terramycine) présents dans l'eau de boisson peuvent être tenus comme partiellement responsables de la polyavitamınose $B$, par modification de la flore microbienne intestinale (3). Enfin, on ne doit pas négliger le mode d'habitat. La claustration, la mise en captivité d'un nombre élevé d'animaux dans un espace restreint pendant un temps prolongé, peuvent intervenir comme facteur déclenchant dans la rupture d'un état de déséquilibre nutritif latent avec apparition concomitante des symptômes.

L'existence d'une avitaminose nette, facilement observable comme le bérıbéri, permet de supposer qu'il s'établit chez l'oiseau de cage d'autres carences, ou précarences, difficilement discernables bien que présentes et sur lesquelles il est néanmoins possible d'agir par un apport global et empirique de complexes polyvitaminés (extrait de levure de bière, graines germées, verdure lait, etc...). La prévention des polycarences larvées ne peut que faciliter la résistance de l'organisme aux agents des maladies infectieuses (8).

\section{Laboratoire national de l'Elevage}

et de Recherches vétérinaires et zootechniques de l'Ouest-Africain - Dakar-Hann

Institut d'Elevage et de Médecine vétérinaire des Poys tropicoux - Massons-Alfort 


\title{
SUMMARY
}

Nate on B polyavitaminosis in cage birds in Senegal

\begin{abstract}
The authors diagnosed several cases of B polvavitaminosis happening with cage birds kept near Dakar, waiting to be exporled.

Keeping and feeding conditions are made precise.

In the Laboratory the authors obtained a quick regression of the sympioms by providing the birds either with yeast extract, thiamin or riboflavin.
\end{abstract}

\section{RESUMEN}

Nota sobre una poliavitaminosis B de los pájaros de jaula en Senegal

\begin{abstract}
Los autores observaron casos de poliavitaminosis B en pájaros criados en pajarera en la región de Dakar, antes de su exportación. Se notaron las condiciones de mantenimiento y de alimentación. En el laboratoric la administración de extracto de levadura, de thımina o de riboflavina provocó una regresión rápida de las síntomas en los pájaros.
\end{abstract}

\section{BIBLIOGRAPHIE}

1. ANONYME. - Ce qu'il faut savoir sur l'entretien des oiseaux en cage. (A primer on caged birds). Mod. vet. Pract., 1965, 46, (12), 176-198.

2. APPLEBY (E. C.). - Quelques observations sur les maladies observées chez les passereaux ef les psittacidés de volières. (Some observations on the diseases of finches and parrot-like birds kept in aviaries). Proc. I st. Congr. Brit. Small Anim. vet. Ass., London, $1958,25-30$ et $31-32$.

3. BASSIN! (E.). - Observations sur les maladies les plus fréquentes du gibier à plumes élevé en captivité. (Osservazioni sulle malattie più comuni della selvaggina allevata in cattività). Nuova Vet., 1960, 36, 197-200.

4. BIESTER (H, E.) et SCHWARTE (L, H.). Les maladies des volailles. (Diseases of poultry). The lowa Stote University Press, 1959.

5. LESBOUYRIES (G.). - La pathologie des oiseaux. Paris, Vigot, 1941.
6. LESBOUYRIES (G.). - Pathologie des oiseaux de basse-cour. Paris, Vigot, 1965.

7. NORRIS (L. C.). - Les progrès réalisés au cours des cinquante dernières années dans l'alimentation des volailles. (The significant advances of the past fifty years in poultry nutrition). Poult. Sci., 1958, 37, 256-274.

8. PANDA (B.) et COMBS (G. F.). - Diminution de la production d'anticorps chez des poussins soumis à un régime déficient en vitamins $A$, en acide pantothénique ou en riboflavine. (Impaired antibody production in chicks fed diets low in vitamin A, pantothenic acid or riboflavin). Proc. Soc. exp. Biol. N. Y., 1963, 113, 530-534.

9. $5 \mathrm{MITH}$ (R. E.). - Influence de la taille et de l'aspect du grit sur la digestibilité des aliments chez la volaille domestique. (The influence of size and surface condition of grit upon the digestibility of feed by the domestic fowl). Conod. J. anim. Sci., 1960, 40, 51-56.

10. WAILLY (Ph. de). - Les oiseaux de cage et de volière. Baillière, 1964. 